\title{
HISTORICAL EARTHQUAKES IN THE REGION OF LEFKADA ISLAND, IONIAN SEA - ESTIMATION OF MAGNITUDES FROM EPICENTRAL INTENSITIES
}

Fokaefs A. and Papadopoulos G.A.

Institute of Geodynamics, National Observatory of Athens, PO Box 20048, 11810, Athens, Greece,anna_fokaefs@hotmail.com, g.papad@gein.noa.gr

\section{ABSTRACT}

Historical documentation of strong shocks for Lefkada Island, Ionian Sea, exists since the 16th century A.D. In this paper we establish a relation between magnitude and maximum intensity from twenty-nine instrumental events that hit the area in the past. Then, on the basis of historical documentary sources we reevaluate the intensities of strong historical earthquakes, their maximum intensity being observed on Lefkada in the time interval from AD1577 to 1911, recalculate their magnitudes on the basis of the magnitude/intensity relation and, finally, compile a new catalogue of historical earthquakes. The results obtained are of importance for the seismicity studies and seismic hazard assessment in the area.

\section{INTRODUCTION}

The Lefkada Island is characterized by strong seismicity and the seismic hazard assessment is of high priority. The instrumental period of seismicity indicates that strong earthquakes with maximum magnitude up to $M_{s} \sim 6.5$ occur frequently in the region of Lefkada particularly in association with (a) the strike-slip fault segment striking NNE-SSW to the west of the island (e.g. 27 November 1914, $M_{s}=6.3,22$ April 1948, $M_{s}=6.5,30$ June 1948, $M_{s}=6.4,14$ August 2003, $M_{s}=6.4$ ) (Figure 1, left), (b) the thrust structure offshore NW Lefkada (e.g. 4 November 1973, $M_{s}=5.9$ ), and (c) no well identified faults between Lefkada and lthaki islands. In this paper an effort has been made to improve magnitudes of a set of twenty-nine strong historical Lefkada earthquakes.
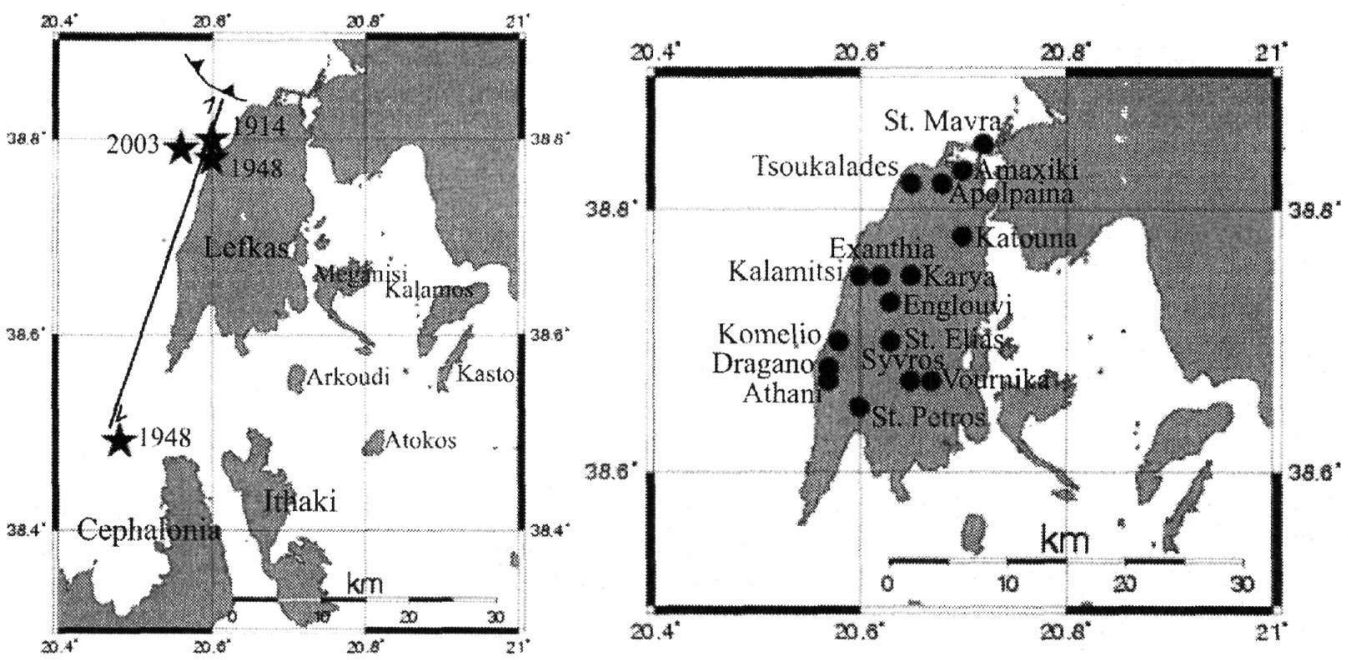

Figure 1.Left: Epicentres of the strong instrumental earthquakes associated with the strike-slip Lefkada fault system. Right: Towns and villages of Lefkada Island, mentioned in Appendix. 


\section{PREVIOUS STUDIES}

Data compilations and descriptions of a large number of strong, historical shocks that hit Lefkada island were published among others by Stamatelos (1870) and Schmidt (1875), while catalogues and / or short descriptions of historical and instrumental events were presented by several scientists including Galanopoulos $(1950,1952,1955,1981)$, Comninakis and Papazachos (1982), Papazachos \& Papazachou (1997), Spyropoulos (1997) and Papadopoulos et al. (2003). From the documentary sources it results that the historical record of earthquakes in Lefkada Island practically started on 16 th century A.D. The historical catalogues containing information about the Lefkada historical earthquakes can be distinguished in two categories. The first one contains the so-called chronological historical catalogues given that the earthquakes are recorded and described in a chronological order. However, this type of catalogues do not include the assessment of focal parameters, like epicentral locations and magnitudes. Such a historical catalogue is the one of Galanopoulos (1952) where thirty strong earthquakes are described.

The second category contains the parametric historical catalogues, like the one of Papazachos and Papazachou (1997), where not only the events are dated and described, but also an effort is made for the epicentral location, focal depth, magnitude and maximum intensity of each one of the events listed to be assessed.

\section{A MAGNITUDE - INTENSITY RELATION}

Magnitudes of historical earthquakes are usually calculated from relations established for instrumental earthquakes where magnitude, $M$, is a function of a particular element of the seismic intensity, $I_{e}$, of the general form $M=f\left(I_{e}\right) . \quad l_{e}$ is either the maximum intensity, $I_{m}$, observed or the perceptibility area for a given value of intensity. The second approach requires for a large number of intensity observation points to be available in order to draw reliable isoseismals. However, a review of several documentary sources regarding the historical Lefkada earthquakes (see in the compilations of Stamatelos 1870, Schmidt,1875, Galanopoulos,1952, Papazachos and Papazachou,1997, Spyropoulos ,1997) reveals that only for a very few number of earthquakes the available number of intensity observation points is adequate to draw isoseismals. Therefore, the first approach has been selected for a reevaluation of historical earthquake magnitudes.

To establish a magnitude- maximum intensity relation we compiled data for a set of twenty-nine instrumental earthquakes with maximum intensity being observed on some spot of the Lefkada island (Table 1). An attempt was made by us to reassess the maximum intensity of these events looking through original macroseismic reports and press reports archived in the Institute of Geodynamics, National Observatory of Athens (NOAGI). This proved successful for a number of five events marked with an asterisk in Table 1 . Then, from regression analysis the relation

$$
M_{s}=0.24 I_{m}+3.92, R^{2}=0.734
$$

was developed (Figure 2). The standard error of $M_{s}$ on $I_{m}$ is 0.25 . The earthquakes that cause maximum intensity on Lefkada have their epicentres very close to the island in either of the three fault structures mentioned above and, therefore, it is practically meaningless for the epicentral distance, $\Delta$, to be inserted as a parameter in relation (1).

\section{INTENSITIES AND MAGNITUDES OF STRONG HISTORICAL EARTHQUAKES}

Historical documentation indicates that a set of fourteen strong earthquakes was reported with estimated maximum intensity on the Lefkada Island in the time interval from AD1577 to 1911 (Table 2). No historical information was found for earthquakes occurring before 1577 . For each one of the fourteen events, $I_{m}$ was reassessed by us from macroseismic descriptions in MM and EMS scales and no remarkable difference was found. In some cases, it was preferred rather to indicate value intervals of the mode $I_{m 1}-I_{m 2}$, that is from intensity $I_{m 1}$ to intensity $I_{m 2}$, than to defermine a single intensity value not well justified by the observation data. Magnitudes were determined from relation 
(1). When mode $I_{m 1}-I_{m 2}$ was preferred, the respective magnitude was calculated as the average of magnitudes $M_{s 1}$ and $M_{s 2}$ determined independently for $I_{m 1}$ and $I_{m 2}$.

Table 1: Data on instrumental Lefkada earthquakes. Maximum intensity values, $I_{m}$, were taken from the NOAGI monthly Bulletins. Events marked with an asterisk in Table 1 indicate intensities reassessed in this paper. Surface-wave magnitudes, $M_{\mathrm{s}}$, were taken from Comninakis and Papazachos (1982) for the time interval from 1911 to 1963 and from the NOAGI earthquake catalogue (http://www.gein.noa.gr) for the time interval from 1971 to 2003. Original NOAGI local magnitudes, $M_{L}$, were converted to surface-wave magnitudes on the basis of the calibration formula $M_{s}=M_{L}+0.5$.

\begin{tabular}{llllll}
\hline a/a & Date $(Y Y Y Y . M M . D D)$ & $\varphi^{\circ}$ N & $\Lambda_{E}{ }_{E}$ & $M_{s}$ & $I_{m}$ \\
\hline 1 & 1911.05 .24 & 38.70 & 20.70 & 5.30 & 7.00 \\
2 & 1914.11 .23 & 38.80 & 20.60 & 4.90 & $4.25^{\star}$ \\
3 & 1914.11 .23 & 38.80 & 20.60 & 5.30 & $6.00^{\star}$ \\
4 & 1914.11 .27 & 38.80 & 20.60 & 6.30 & 9.00 \\
5 & 1915.02 .20 & 38.80 & 20.70 & 5.00 & 4.00 \\
6 & 1915.08 .08 & 38.50 & 20.70 & 5.00 & 3.00 \\
7 & 1915.08 .10 & 38.50 & 20.70 & 5.30 & 5.00 \\
8 & 1921.05 .10 & 38.70 & 20.70 & 5.40 & 7.00 \\
9 & 1921.10 .25 & 39.00 & 20.50 & 5.30 & 5.00 \\
10 & 1923.10 .09 & 38.80 & 21.00 & 5.00 & 5.00 \\
11 & 1938.03 .11 & 38.80 & 20.60 & 5.60 & 7.00 \\
12 & 1938.03 .13 & 38.80 & 20.60 & 5.80 & 8.00 \\
13 & 1948.04 .22 & 38.70 & 20.50 & 6.50 & $9.00^{\star}$ \\
14 & 1948.06 .30 & 38.80 & 20.60 & 6.40 & $10.00^{\star}$ \\
15 & 1951.01 .09 & 38.80 & 20.60 & 5.00 & 4.00 \\
16 & 1953.09 .15 & 38.50 & 20.80 & 5.00 & 4.00 \\
17 & 195710.8 & 38.90 & 20.60 & 5.20 & 6.00 \\
18 & 1960.02 .23 & 39.00 & 20.60 & 5.00 & 5.25 \\
19 & 1961.12 .18 & 38.80 & 20.60 & 5.00 & 5.25 \\
20 & 1963.06 .04 & 38.90 & 20.50 & 5.00 & 6.25 \\
21 & 1971.04 .19 & 38.70 & 20.50 & 5.30 & $7.00^{\star}$ \\
22 & 1973.11 .04 & 38.78 & 20.55 & 5.90 & 7.25 \\
23 & 1976.01 .18 & 38.70 & 20.40 & 5.70 & 7.25 \\
24 & 1978.09 .14 & 38.90 & 20.60 & 5.10 & 5.25 \\
25 & 1980.04 .12 & 38.60 & 20.30 & 5.60 & 5.00 \\
26 & 1988.04 .24 & 38.84 & 20.33 & 5.00 & 6.00 \\
27 & 1994.11 .29 & 38.66 & 20.46 & 5.40 & 6.00 \\
28 & 1994.12 .01 & 38.69 & 20.55 & 5.30 & 5.00 \\
29 & 2003.08 .14 & 38.79 & 20.56 & 6.40 & 8.00 \\
\hline
\end{tabular}

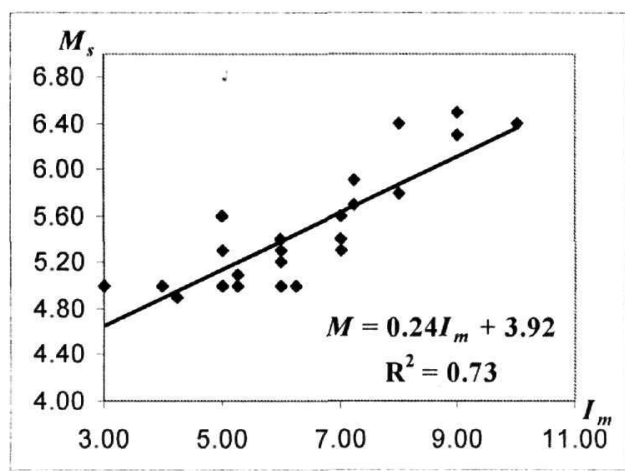

Figure 2. The relation between $M_{s}$ and $I_{m}$ developed by a set of 29 instrumental earthquakes.

As for the event dates no evidence was found to substantiate some corrections. An effort was made to provide dates in the New Style (Gregorian) although in some particular cases it is not clear whether or not the earthquake dates given in the original documents are in the Old (Julian) or the 
New Style. However, we introduced corrections in the origin time for several events. Our estimates of the epicentral 'coordinates practically do not deviate from those proposed by others who were based on the proximity of the epicenter to the meizoseismal region. More details about the reevaluation of the earthquake parameters can be found in Appendix.

Table 2. Parameters of the Lefkada historical earthquakes; $\varphi N$ and $\lambda E$ are epicentral coordinates, $I_{m}=$ maximum intensity, $M_{s}=$ surface-wave magnitude. $P$ and FP denote Papazachos and Papazachou $(1997,2003)$ and the present paper, respectively.

\begin{tabular}{llllllll}
\hline Date & $\varphi N(\mathrm{P})$ & $\lambda E(\mathrm{P})$ & $I_{m}(\mathrm{P})$ & $I_{m 1}-I_{m 2}(\mathrm{FP})$ & $M_{s}(\mathrm{P})$ & $M_{s 1}-M_{s 2}$ & $M_{s}(\mathrm{FP})$ \\
\hline 1577 & & & 8.0 & $?$ & 6.20 & $?$ & $?$ \\
16120526 & 38.8 & 20.8 & 8.0 & $9.0-10.0$ & 6.50 & $6.10-6.40$ & 6.25 \\
16131002 & 38.8 & 20.8 & 8.0 & $9.0-10.0$ & 6.40 & $6.10-6.40$ & 6.25 \\
16250618 & 38.8 & 20.7 & 9.0 & 10.0 & 6.60 & & 6.40 \\
16300702 & 38.8 & 20.8 & 9.0 & 10.0 & 6.70 & & 6.40 \\
17041122 & 38.8 & 20.7 & 9.0 & 10.0 & 6.30 & & 6.40 \\
17220605 & 38.7 & 20.6 & 8.0 & $8.0-9.0$ & 6.40 & $5.90-6.10$ & 6.00 \\
17230222 & 38.6 & 20.65 & 8.0 & 9.0 & 6.70 & & 6.10 \\
17691012 & 38.8 & 20.6 & 9.0 & 10.0 & 6.70 & & 6.40 \\
17830323 & 38.71 & 20.61 & 10.0 & $10.0-11.0$ & 6.70 & $6.40-6.60$ & 6.50 \\
1815 & 38.8 & 20.7 & 8.0 & 9.0 & 6.30 & & 6.10 \\
18200221 & 38.8 & 20.6 & 9.0 & $8.0-9.0$ & 6.40 & $5.90-6.10$ & 6.00 \\
18250119 & 38.7 & 20.6 & 10.0 & $9.0-10.0$ & 6.50 & $6.10-6.40$ & 6.25 \\
18691228 & 38.85 & 20.80 & 10.0 & 10.0 & 6.40 & & 6.40 \\
\hline
\end{tabular}

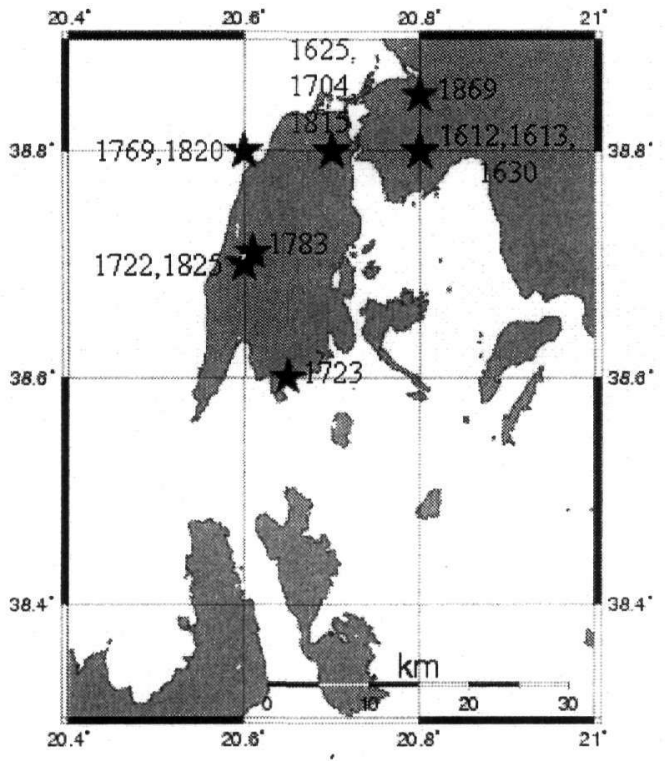

Figure 3. Epicentres of the events listed in Table 2 reported by Papazachos and Papazachou (1997).

\section{CONCLUSIONS}

Several documentary sources were utilized to recalculate surface-wave magnitude, $M_{s}$, for a number of fourteen strong, historical earthquakes occurring in Lefkada from 1577AD to 1869. For most of the events examined only a small number of intensity observation points are available and, therefore, we were unable to calculate magnitudes from empirical formulas that involve perceptibility areas. From a set of twenty-nine earthquakes of $M_{s}$ ranging from 4.90 to 6.5 and occurring in Lefkada during the instrumental era of seismicity, it was found that data on magnitude and maxi- 
mum intensity, $I_{m}$, fit well-enough the local relation $M_{s}=0.24 I_{m}+3.92\left(R^{2}=0.734\right)$. The standard error of $M_{\mathrm{s}}$ on $I_{\mathrm{m}}$ is 0.25 . From the documentary sources, $I_{\mathrm{m}}$ was reevaluated for each historical event and then the respective magnitude was calculated from relation (1). The revised magnitudes are systematically lower by 0.26 magnitude units on average with respect to those calculated by Papazachos and Papazachou $(1997,2003)$. They seem, however, to be more realistic since they are closer to magnitudes determined for strong instrumental earthquakes of Lefkada. The results indicate that the methodology applied works and that it could be applied for the calculation of historical earthquake magnitudes by producing local $M_{s} / I_{m}$ relations in other regions of Greece.

\section{REFERENCES}

Albini, P., 1999. Venetian documents on Earthquakes within and at the western bounders of the Ottoman Empire (17th - 18th centuries). Proceedings of Symposium on Natural Disasters in the Ottoman Empire, held in Rethymnon, Crete 10-12 January 1997, 67-88.

Ambraseys, N.N. and Finkel, C.F., 1999. Unpublished Ottoman information on the seismicity of the Balkans during the period 1500-1800. Proceedings of Symposium on Natural Disasters in the Ottoman Empire, held in Rethymnon, Crete 10-12 January 1997, 89-107.

Barbiani, D.G. and Barbiani B.A., 1864. Memoires sur les tremblements de terre dans I' ile de Zante, Presented by A. Perrey in Academic Imperiale des Sciences, 1-112, Dijon.

Comninakis, P.E. and Papazachos, B.B, 1982. A catalogue of historical earthquakes in Greece and surrounding area: 479B.C. - 1900A.D., Geophys. Lab. Univ. of Thessaloniki Publ., 5, 1-24.

Galanopoulos, A.G., 1950. Die Seismizität der Insel Leukas, Gerl. Beitr. Geophys.,63,1-15.

Galanopoulos, A.G., 1952. Die seismizität der Insel Leukas, Gerl. Beit. . Geophys., 62,256-263.

Galanopoulos, A.G., 1955. The Seismic Geography of Greece, Ann. Geol. Pays Hellen., 6, 83-121.

Galanopoulos, A.G., 1981. The earthquake potential of Greece, Ann. Geol. Pays Hellen., 30, 648-724.

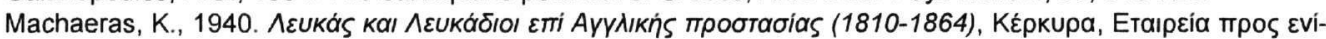

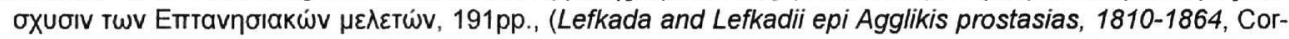
fu, Edit. Etaeria pros enischisin ton Eptanesiakon meleton, 191pp. )

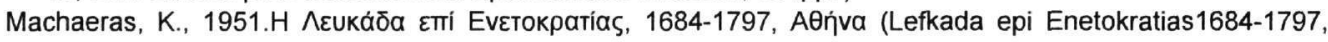
Athens.)

Papadopoulos G.A., Karastathis V.K., Ganas A., Pavlides Sp. , Fokaefs A. and Orfanogiannaki K., (2003). The Lefkada, Ionian Sea (Greece), Shock (Mw 6.2) of 14 August 2003: Evidence for the Characteristic Earthquake from Seismicity and Ground Failures, Earth, Planets \& Space, 55, 713-718.

Papazachos, B.B, and Comninakis, P.E, 1982. A catalogue of earthquakes in Greece and surrounding area: 1901 - 1980, Geophys. Lab. Univ. of Thessaloniki Publ., 5, 1-24.

Papazachos, B.C. and Papazachou C. B., 1997. The earthquakes of Greece, Thessaloniki, Ziti Edit.,304 pp.

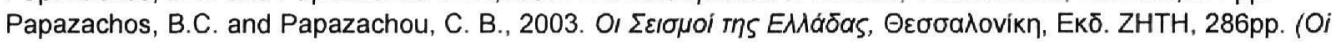
seismoi tis Ellados, Thessaloniki, Ziti Edit., 286pp.)

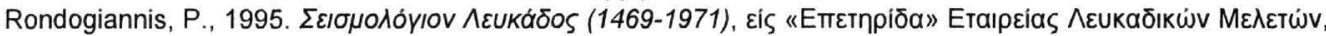

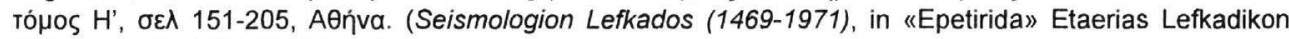
Meleton, v. H, 151-205, Athens)

Sathas, K., 1867. Mعбaı 2222/ 2223, 2225, (Mesaionikon Seismologion tis Ellados kai idios tis Kefallinias kai Lefkados, "AION», sh. 2222/2223, 2225.)

Schmidt, F.J., 1875. Studien über Erdbeben, Leipzig, Carl Scholtze, 360pp.

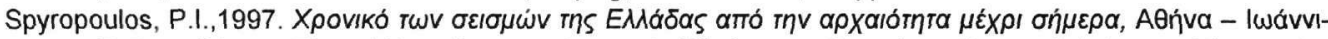
va, Екठ̄. $\Delta \omega \delta \bar{\omega} v \eta, 453 \mathrm{pp}$, (Chroniko ton seismon tis Elladas apo tin archaeotita mechri simera, Athens - loannina, Dodoni Edit., $453 \mathrm{pp}$.)

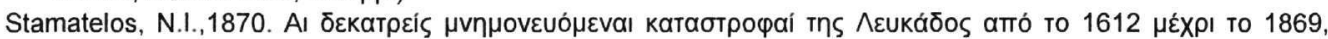

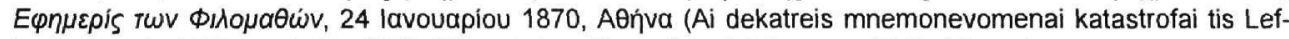
kados apo to 1612 mechri to 1869, Efimeris ton Filomathon, 24 January 1870, Athens).

\section{APPENDIX: REVISION OF EARTHQUAKE EVENTS}

\section{7}

According to an Ottoman source, the walls of Ayamavra (Lefkada) castle were shifted because of an earthquake and needed repair (Ambraseys and Finkel, 1999). Based on this information, Pa- 
pazachos and Papazachou (2003) assigned an intensity VIII in Lefkada and magnitude 6.2 for the earthquake. However, we do not proceed with intensity and magnitude calculations because the available macroseismic information is inadequate.

Barbiani and Barbiani (1864), Sathas (1867), Stamatelos (1870), Machaeras (1940, 1951), Rondogiannis (1995) and Albini (1999), reproduced local archives and memories describing several earthquake destructions occurring in Lefkada from 1612 to 1869 . Little information about the 1869 event has been supplied also by Schmidt (1875). The above texts constitute the main bulk of sources used by us to evaluate seismic intensities. Some of these publications were also reproduced by several authors (e.g. Galanopoulos, 1952, Papazachos and Papazachou, 1989,1997, 2003, Spyropoulos, 1997). The strong earthquakes of 23 June 1741 and 22 July 1767 were considered by some authors as Lefkada earthquakes. However, we did not evaluated them since both had their macroseismic epicenters not in Lefkada but in the island of Cephalonia.

\section{May 26}

According to the documentary sources two earthquakes occurred causing great damage to the

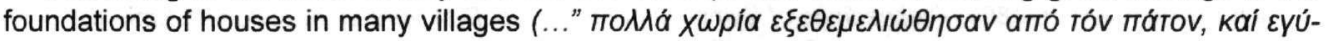

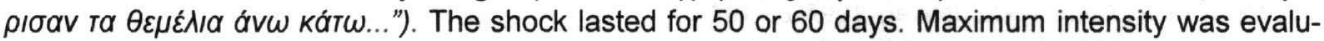
ated as equal either to $I_{m 1}=9$ or to $I_{m 1}=10$, and then from equation (1) we gut magnitudes $M_{s 1}=6.1$ and $M_{s 2}=6.4$ respectively. The average $\left(M_{s}(F P)=6.25\right)$ of $M_{s 1}$ and $M_{s 2}$ was adopted as the most reliable estimate of the earthquake magnitude. The occurrence time of the earthquake should be corrected to 8 a.m.

\section{October 02}

The sources indicate that this event was of similar destructive effects with the 1612 one and, therefore, the estimated intensities and magnitudes were again found to be $I_{m 1}=9, I_{m 1}=10, \quad M_{s 1}=$ $6.1, M_{s 2}=6.4, M_{s}(\mathrm{FP})=6.25$.

\section{June 18}

This earthquake caused the collapse of all the houses and shops in Amaxiki, that is in the main

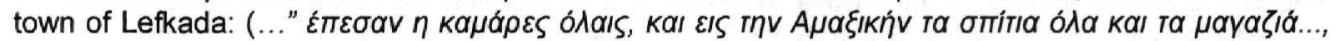

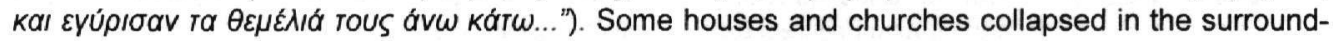
ing villages too, like in Tsoukalades. We estimated $I_{m}=10$ and $M_{s}(\mathrm{FP})=6.4$.

\section{July 02}

The earthquake destruction caused the death of many people as many houses collapsed in Amaxiki, Kastro and Katouna where the trees were unrooted too. In some villages the earthquake broke down all the houses. We estimated $I_{m}=10$ and $M_{s}(\mathrm{FP})=6.4$.

\section{November 22}

A terrible earthquake occurred during the night and the shocks continued for many days. All houses and churches in Amaxiki and Kastro collapsed except St Athanasios' church that was made of wood. Thirteen people died in Amaxiki and three in Kastro. This shock reportedly affected the

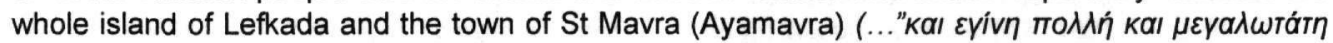

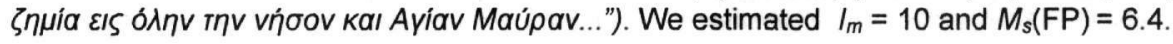

\section{June 06}

Two sequential earthquakes happened and many houses collapsed in Amaxiki, Athani, Damiliani and St. Petros. We estimated $I_{m 1}=8, I_{m 1}=9, M_{s 1}=5.9, M_{s 2}=6.1, M_{s}$ (FP) $=6.0$.

\section{February 22}

The mainshock was preceded by a strong shock on 20th of February. The mainshock caused the collapse of several houses while many others damaged especially in Amaxiki. The place set apart for women in the church of Evagelistria collapsed and the Latin church Pantokrator was pulled down as well. Aftershocks lasted until May of 1723 . We estimated $I_{m}=9$ and $M_{s}(F P)=6.1$. 


\section{October 12}

More than $50 \%$ of the houses destructed while the rest suffered serious damage. Great damage was caused to the houses and churches. The east walls of the castle and nearly all churches destructed. Seven people killed. We estimate $I_{m}=10$ and $M_{s}(F P)=6.4$.

\section{March 23}

This earthquake was preceded by two strong shocks on the $9^{\text {th }}$ and11th of March. The village of Athani was completely destroyed, while many houses in St. Petros, Dragano, Komelio, Kalamitsi, Damiliani, Exantheia, St. Elias, Englouvi, Syvros and Vournika were pulled down. Large pieces of the mountains were landslided causing additional destruction. Sixty people were killed by the earthquake. The aftershocks continued till August causing additional damage. We estimated $I_{m 1}$ $=10, I_{m 1}=11, M_{s 1}=6.4, M_{s 2}=6.6, M_{s}(\mathrm{FP})=6.5$.

1815

This strong earthquake caused the collapse of many buildings and death to many people of unidentified number. We suggested $I_{m}=9$ and calculated $M_{s}(F P)=6.1$.

\section{February 21}

This earthquake caused the collapse of many houses and churches, while the city walls were harmed and in the central square a subsidence occurred. We estimated $I_{m 1}=8, I_{m 1}=9, \quad M_{s 1}=5.9$, $M_{s 2}=6.1, M_{s}(\mathrm{FP})=6.0$.

\section{January 19}

The earthquake was great and destructed the town of Lefkada while most of the villages damaged. Only in the town of Lefkada sixty people killed and another eighty injured. Victims were reported from the villages as well. We estimated $I_{m 1}=9, I_{m 1}=10, M_{s 1}=6.1, M_{s 2}=6.4, M_{s}(\mathrm{FP})=6.25$.

\section{December 28}

The town of Lefkada changed to a pile of ruins and only 20 to 25 houses remained undamaged. Fifteen people died. Serious damage was observed in Tsoukalades, Katouna and Apoplaia, while in Karya, Sphakiotes and Exanthia suffered less. We estimated $I_{m}=10$ and $M_{s}(\mathrm{FP})=6.4$. 